\title{
Filtros processuais de acesso às Cortes Constitucionais: a Questão Prioritária de Constitucionalidade e os filtros de acesso ao Conselho Constitucional Francês
}

\author{
Procedural criteria to access Constitutional Courts: the Priority Incident of Constitutionality \\ and filters to access French Constitutional Council
}

\begin{abstract}
Resumo
O presente artigo inaugura uma série que se propõe a analisar os filtros de acesso a Cortes Constitucionais em diversos sistemas democráticos. Este trabalho analisa especificamente a questão prioritária de constitucionalidade (QPC) e os filtros de acesso ao Conselho Constitucional Francês. Assim, trata do sistema normativo e da práxis relacionados a esse instrumento introduzido naquele sistema em 2008, marcado até então, pelo caráter a priori, ou seja, um texto infraconstitucional apenas poderia ser objeto de controle pelo Conselho Constitucional até a sua aprovação pelo parlamento. Com a questão prioritária, introduz-se o controle a posterioi,

i.e., de diplomas já vigentes, mediante a iniciativa de uma das partes em um processo. Para que o Conselho Constitucional seja efetivamente provocado a se pronunciar, é necessário ultrapassar filtros de acesso em dois níveis: o primeiro, realizado pelo juiz da causa; o segundo, por uma das cortes supremas (Conselho de Estado ou Corte de Cassação).
\end{abstract}

Palavras-chave: questão prioritária de constitucionalidade. Conselho Constitucional Francês. controle de constitucionalidade. filtros.

\begin{abstract}
This paper launches a series intended to analyze filters to access constitutional courts`s jurisdictions in some democracies. It specifically analyses the priority incident of constitutionality (question prioritaire de constitutionnalité - QPC) and the filters to access French Constitutional Council. Thus, it deals with the normative system and the praxis related to this procedural instrument introduced into french juciail review system in 2008 , marked by then, by the character a priori, i.e., legislation only could be controlled by Constitutional Council until its adoption by Parliament. The priority incident of constitutionality introduces a posteriori judicial review in France, i.e., judicial review concerning already edited legislation. For the Constitutional Council to be effectively provoked to pronounce, it is necessary to overcome access filters on two levels: the first, carried out by the judge of the case; the second, by one of the Supreme Courts (Council of State or Court of Cassation).

Keywords: priority constitutional incident. French Constitutional Council. judicial review. filter.
\end{abstract}

\section{Introdução}

Este artigo tem por fim inaugurar uma série de trabalhos analisando as Cortes, Tribunais e Conselhos Constitucionais de algumas democracias contemporâneas, bem como as formas como o jurisdicionado pode acessar a jurisdição desses tribunais constitucionais para a obtenção de um pronunciamento sobre a constitucionalidade/inconstitucionalidade de um ato normativo.

A intenção da série de estudos inaugurada pelo presente trabalho é permitir aos interessados no assunto a compreensão das especificidades dos sistemas a serem analisados, tanto como seus tribunais 
constitucionais são estruturados, quanto como se pode acessar as sua jurisdições, em tempos em que o controle de constitucionalidade exercitado tribunais constitucionais é uma tônica nas principais democracias contemporâneas.

A pesquisa se torna particularmente instigante na atual quadra histórica, em que, no Brasil, o Supremo Tribunal Federal está à beira da inviabilização, entre outras consequências, em razão de suas amplas competências e da quantidade de julgamentos que tem sido instado a prolatar a cada ano.

Quanto a esse assunto, existe um certo consenso entre os especialistas brasileiros de que o Supremo Tribunal Federal está sendo crescentemente acionado e que uma reconfiguração é necessária ${ }^{1}$ Umas dessas reconfigurações se daria precisamente quanto à reformulação de filtros de acesso, em um momento em que a repercussão geral, a sistemática dos recursos repetitivos e a tese da ofensa reflexa parecem não ser suficientemente eficazes para filtrar adequadamente os recursos extraordinários, um dos principais instrumentos por meio dos quais o Supremo Tribunal Federal exercita a jurisdição constitucional.

Na sequência deste trabalho, que analisa o sistema francês e os filtros de acesso à jurisdição do Conselho Constitucional pela via da questão prioritária de constitucionalidade, o projeto é dar continuidade com a análise dos sistemas estadunidense e canadense, culminando com o estudo do sistema brasileiro e os principais aspectos dos sistemas estudados em perspectiva comparada.

Ao inaugurar-se a série com o sistema francês, encerra-se parcialmente uma etapa de estudos empreendida em sede de estágio pós-doutoral na Universidade de Paris I Panthéon-Sorbonne, com profícua troca de ideias com diversos estudantes e professores, notadamente com a Professora Marie-Anne Cohendet e o Professor Dominique Rousseau.

Neste trabalho, analisar-se-á a configuração do Conselho Constitucional da França, com algumas de suas particularidades, bem como a novel questão prioritária de constitucionalidade (QPC) e os filtros existentes naquele sistema para que o jurisdicionado possa acessar o Conselho Constitucional com a finalidade de obter uma manifestação acerca da constitucionalidade/inconstitucionalidade de uma disposição legislativa.

O problema a ser analisado é a questão dos filtros de acesso aos tribunais constitucionais, de sorte a que não sejam excessivamente rígidos que impeçam ou tornem extremamente difícil o acesso às suas jurisdições, de um lado; e, de outro, que não sejam excessivamente elásticos, de forma a vulgarizar os julgamentos dos órgãos de cúpula, a ponto de até mesmo inviabilizar a sua rotina de trabalho.

O objetivo dos trabalhos que essa série inaugura é analisar filtros de acesso em sistemas constitucionais alienígenas, em ordem a identificar seus vícios e virtudes, servindo, assim, de parâmetro de comparação com o nosso sistema. Ao final da série, o projeto contará com um artigo-síntese entre as características consideradas mais importantes nos diversos sistemas em perspectiva comparada com o recurso extraordinário e os filtros de acesso ao Supremo Tribunal Federal.

A hipótese de trabalho é de que os filtros de acesso são válvulas importantes a serem utilizadas no sentido de equilibrar o acesso do jurisdicionado aos tribunais constitucionais, de um lado, e, de outro, que possibilitem apenas a remessa aos tribunais constitucionais de casos e temas dotados de certa relevância e em uma quantidade que permita um fluxo adequado de trabalho, em ordem a preservar a qualidade das decisões, bem como a integridade do sistema.

A metodologia adotada foi a revisão bibliográfica.

1 Relatório Supremo em Ação. Conselho Nacional de Justiça. Disponível em http://www.cnj.jus.br/pesquisasjudiciarias / supremo-em-acao. Acesso em 6 de novembro de 2017. O diagnóstico aqui apresentado cobre o período de 2009 a 2016, evidenciando a complexa tarefa que compete ao STF. São numerosos, complexos e variados os processos que aportam na Corte: no período de oito anos, tramitaram no Supremo Tribunal Federal 723.579 processos, contabilizando 64.356 partes e 842.573 decisões. Assim, os dados aqui sistematizados dão conta de um Supremo Tribunal Federal excessivamente acionado (sobretudo quando comparado a outras cortes supremas ao redor do mundo), e que vem respondendo de forma crescente a essa demanda. 


\section{O Conselho Constitucional Francês}

As primeiras constituições da França pós-revolucionária tinham por finalidade reconhecer direitos fundamentais, notadamente de primeira geração (garantias e liberdades individuais). No entanto, quem garantiria a força das constituições, já que os juízes eram vistos como “cúmplices” do Antigo Regime?

Dessa forma, ao longo do tempo, o papel de exercer o controle de constitucionalidade dos atos normativos passou do Diretório Executivo (art. 26 da Carta de 14.1.1852) ao Senado Conservador (arts. 21 e 37 da Carta de 13.12.1799). Na Carta de 27.10.1946, por sua vez, foi criado o Comitê Constitucional, formado por parlamentares e pelo Presidente da República, com a competência de verificar se os projetos de lei, quanto ao procedimento, supunham uma revisão da Constituição (arts. 91 a 93)².

Com a Carta de 4 de outubro de 1958, que inaugurou a Quinta República, o parlamentarismo francês foi profundamente reformulado. No contexto dessas mudanças, foi criado o Conselho Constitucional, concebido como órgão auxiliar do Governo, sem vinculação com o Poder Judiciário, a exercitar o controle de constitucionalidade como regulação entre os poderes políticos mediante controle abstrato de atos normativos infraconstitucionais, tendo evoluído para a possibilidade de um controle substantivo com a decisão de 16 de julho de 1971 (liberdade de associação) e a reforma constitucional de 29 de outubro de $1974^{3}$.

O Conselho Constitucional é composto de nove membros, cada terço nomeado pelo Presidente da República, pelo Presidente da Assembleia Nacional e pelo Presidente do Senado. A sua renovação se dá por terços a cada três anos, de forma que cada um dos Presidentes tem a prerrogativa de nomear um membro do Conselho a cada triênio. Até a revisão constitucional de 2008, não não havia qualquer dispositivo fixando condições de idade, profissão ou competência, tampouco qualquer necessidade de consulta prévia, de forma que as três autoridades com poder de nomeação exerciam-no com ampla liberdade ${ }^{4}$.

Em comparação com as exigências da maioria das constituições europeias no que concerne às nomeações para o cargo de juiz constitucional, o sistema francês suscitava inúmeras críticas, que poderiam ser resumidas no excesso de politização das nomeações. À falta de constrangimentos normativos, os três Presidentes gozavam de ampla discricionariedade, inclusive para nomear os seus amigos políticos pessoais ${ }^{5}$.

Para alterar essa configuração é que a reforma constitucional de julho de 2008 introduziu um controle parlamentar sobre as nomeações do Conselho. O artigo 56 reformado dispõe, com efeito, que o poder de nomeação do Presidente da República se exerce após parecer público da comissão permanente de cada uma das Casas do Parlamento e que ele não pode realizar a nomeação caso os votos contrários em cada comissão representem, ao menos, três quintos dos votos. Esse controle parlamentar também é exercido sobre o poder de nomeação dos presidentes do Senado e da Assembleia Nacional por suas respectivas comissões permanentes ${ }^{6}$.

Característica que se destaca pela sua peculiaridade, tradicionalmente o Conselho Constitucional da França exercitava tão-somente o controle de constitucionalidade a priori, ou seja, antes do início da vigência do ato normativo, mas não a posteriori, sendo esse elemento apontado como importante lacuna no controle de constitucionalidade francês.

2 ALMEIDA, Domingos Augusto Paiva de. O controle de constitucionalidade na França. Revista de Informação Legislativa, Brasília, n. 144, ano 36, p. 197-210, out-dez/1999, p. 198.

3 ALMEIDA, Domingos Augusto Paiva de. O controle de constitucionalidade na França. Revista de Informação Legislativa, Brasília, n. 144, ano 36, p. 197-210, out-dez/1999, p. 200.

4 ROUSSEAU, Dominique. Droit du contentiux constitutionnel. Paris: Editions Montchrestien. 9eme edition. 2010, p. 59 .

5 p. 59 .

ROUSSEAU, Dominique. Droit du contentiux constitutionnel. Paris: Editions Montchrestien. 9eme edition. 2010,

ROUSSEAU, Dominique. Droit du contentiux constitutionnel. Paris: Editions Montchrestien. 9eme edition. 2010, 
Para resolver essa lacuna é que o Governo Miterrand apresentou em 1990 projeto de reforma constitucional, instituindo a exceção de inconstitucionalidade, que consistiria em suspender o processo judicial para que o Conselho Constitucional se manifestasse sobre a arguição de inconstitucionalidade. Todavia, o intento foi barrado no Senado ${ }^{7}$.

Assim é que durante os primeiros cinquenta anos de vigência da Constituição (1958-2008), a concepção inicial de controle de constitucionalidade foi mantida, ou seja, o controle exclusivamente a priori, antes da promulgação da lei, mediante iniciativa reservada às autoridades listadas expressamente pela Constituição, com a exclusão, a contrario sensu, da iniciativa dos particulares ${ }^{8}$.

No entanto, a práxis demonstrou, ao menos, dois inconvenientes desse modelo de controle de constitucionalidade exercido pelo Conselho Constitucional em caráter exclusivamente a priori:

i. a impossibilidade de controle a posteriori confere às leis promulgadas uma presunção absoluta e inquestionável de constitucionalidade. Assim, uma lei em vigor, mesmo que eventualmente contrária à Constituição, não poderia ser declarada inconstitucional pelo Conselho nem pelas jurisdições ordinárias (judiciárias ou administrativas), o que levaria, em último grau, a um déficit de Estado de Direito;

ii. a impossibilidade de iniciativa de controle de constitucionalidade pelos particulares parecia pouco democrática, especialmente em comparação aos numerosos países da Europa cujas constituições permitiam a iniciativa do particular;

iii. a inexistência de iniciativa do particular gerava uma incoerência no sistema, pois, de outro lado, os particulares poderiam perante as instâncias ordinárias suscitar o controle de "convencionalidade" de leis já vigentes ${ }^{9}$.

Em face dessas lacunas da "excepcionalidade francesa" é que a Constituição de 1958 foi reformada em 23 de julho de 2008, meio século após a sua edição, para introduzir, a partir do artigo 61-1, um novo modelo de controle de constitucionalidade, representado pela questão prioritária de constitucionalidade (QPC), nomeada dessa maneira pela Lei Orgânica n. 2009-1523, de 10 de dezembro de 2009, que foi declarada constitucional pelo Conselho Constitucional pela Decisão 2009-595 DC de 2 de dezembro de $2009^{10}$.

Por esse mecanismo processual, a parte em um processo tramitando perante a jurisdição ordinária pode suscitar a inconstitucionalidade de uma lei, podendo chegar, a depender de serem ultrapassados certos filtros de acesso que serão analisados no próximo tópico, ao Conselho Constitucional.

A questão é dita prioritária porque o juiz do feito deverá analisá-la em primeiro lugar, ou seja, com prioridade em relação ao mérito da causa. Esse instrumento abre, assim, às partes processuais comuns o direito de demandar a anulação de uma lei que se estima contrária à Constituição, consagrando a possibilidade do controle constitucional a posteriori de leis perante o Conselho Constitucional, dentro das condições a serem analisadas em seguida ${ }^{11}$.

Sobre esse instrumento, que alterou profundamente as competências dos Conselho Constitucional e o próprio controle de constitucionalidade de leis na França, é que se tratará no capítulo seguinte.

\section{A questão prioritária de constitucionalidade (QPC)}

7 ALMEIDA, Domingos Augusto Paiva de. O controle de constitucionalidade na França. Revista de Informação Legislativa, Brasília, n. 144, ano 36, p. 197-210, out-dez/1999, p 207.

8 CONSTANTINESCO, Vlad; PIERRÉ-CAPS, Stéphane. Droit Constitutionnel Français. Paris: Licence Puf, 2010, p. 220.

CONSTANTINESCO, Vlad; PIERRÉ-CAPS, Stéphane. Droit Constitutionnel Français. Paris: Licence Puf, 2010, p. 
Areforma constitucionalde 23 dejulhode2008, queintroduziua questão prioritária deconstitucionalidade (QPC) pela via do art. 61-1 da Constituição de 1958, teve um triplo objetivo:

- conferir um novo direito ao jurisdicionado ao lhe permitir fazer valer os seus direitos de estatura constitucional;

- expurgar da ordem jurídica dispositivos inconstitucionais;

- assegurar a proeminência da Constituição na ordem interna ${ }^{12}$.

A QPC é um instrumento processual que permite a qualquer pessoa que seja parte em um processo sustentar que uma disposição legislativa atenta contra os direitos e liberdades garantidos pela Constituição. Se os requisitos de admissibilidade da QPC estiverem presentes, caberá ao Conselho Constitucional, mediante reenvio pelo Conselho de Estado ou pela Corte de Cassação, se pronunciar e, se for o caso, abrogar a disposição legislativa em questão.

Não é demais esclarecer, neste ponto, que a organização judiciária francesa é complexa e peculiar, comportando duas ordens jurisdicionais muito bem separadas e delimitadas em seus feixes competenciais: a ordem da jurisdição judiciária (ou comum) e a ordem da jurisdição administrativa.

Para além da competência, essas jurisdições apresentam entre si grandes diferenças, quais sejam: suas estruturas são específicas, os status de seus membros também, bem como sua independência não é assegurada da mesma forma. Elas se aproximam nos planos das garantias aos jurisdicionados e do processo. No mais, são distintas. Essa distinção suscita muitas vezes alguns problemas práticos, pois é justamente na separação de competências entre a jurisdição judiciária e a jurisdição administrativa que a complexidade atinge o seu ponto culminante ${ }^{13}$.

Se se pode falar em ordem judiciária ou em ordem administrativa, é essencialmente porque o conjunto de órgãos jurisdicionais que as compõem estão direta ou indiretamente ligados à Corte de Cassação, do lado da jurisdição judiciária, ou ao Conselho de Estado, do lado da jurisdição administrativa. Em outras palavras, há dois grandes troncos na ordem jurisdicional francesa, sendo a Corte de Cassação ou o Conselho de Estado os órgãos de cúpula respectivos, por essa razão chamados de Cortes Supremas.

Essa distinção tem causas históricas remontando ao princípio da separação das autoridades administrativas e judiciárias, proclamado pela Revolução Francesa, bem como à desconfiança com que era vista a jurisdição judiciária ${ }^{14}$. Dessa forma, os processos que dizem respeito à Administração Pública, grosso modo, estão submetidos à justiça administrativa.

Após essa breve digressão, retornando à QPC, assim estabelecem os dispositivos constitucionais a ela pertinentes:

\section{Artigo 61-1}

Desde que, por ocasião de um processo em curso, seja suscitado que uma disposição legislativa atenta contra os direitos e liberdades garantidos pela Constituição, o Conselho Constitucional pode ser provocado a se manifestar sobre essa questão por reenvio do Conselho de Estado ou da Corte de Cassação, que devem se pronunciar em um prazo determinado.

Uma lei organica determinará as condicões de aplicabilidade deste artigo.

Artigo 62

(...)

Uma disposição declarada inconstitucional com fundamento no art. 61-1 deve ser abrogada desde a publicação da decisão do Conselho Constitucional ou de uma data ulterior fixada por essa decisão. O Conselho Constitucional

12 GUILlaUme, Marc. La Question Prioritaire de Constitutionnalité. Disponível em http://www.conseilconstitutionnel.fr /conseil-constitutionnel/francais/la-question-prioritaire-de-constitutionnalite/decouvrir-la-qpc/laquestion-prioritaire-de-constitutionnalite-par-marc-guillaume.138360.html. Acesso em 09/09/2016.

13 PACTET, Pierre. Que sais-je? Les institutions françaises. Presses Universitaires de France. 1983, 3. e. edição, Paris, Presses Universitaires de France, p. 106.

14 PACTET, Pierre. Que sais-je? Les institutions françaises. Presses Universitaires de France. 1983, 3.a edição, Paris, Presses Universitaires de France, p. 101. 
tem o poder de determinar as condicões e limites nos quais os efeitos decorrentes do dispositivo são suscetíveis de revisão.

As decisões do Conselho Constitucional são irrecorríveis. Elas são vinculantes em relação aos poderes e a todas as autoridades administrativas e jurisdicionais.

Por efeito do artigo 61-1 da Constituição e da Lei Orgânica de 10 de dezembro de 2009, toda pessoa poderá, em sede de um processo, levantar a contrariedade de uma disposição legislativa com a Constituição. Essa questão poderá ser levantada perante todas as jurisdições, em qualquer fase do procedimento. Caso admitida pelo juiz do feito, será reenviada ao Conselho de Estado e à Corte de Cassação, que se assegurarão de que os critérios de reenvio estejam presentes. Essas cortes supremas (Conselho de Estado de Corte de Cassação), caso preenchidas algumas condições a serem analisadas à frente, transmitirão a questão ao Conselho Constitucional, único juiz da constitucionalidade da disposição legislativa, que poderá, se for o caso, abrogá-la.

Verifica-se, a partir do art. 61-1, que o objeto da QPC é a inconstitucionalidade de uma disposição legislativa que atente contra os direitos e liberdades garantidos pela Constituição, suscitada em sede de um processo em curso. Caso o juiz da causa lhe confira admissibilidade, em um primeiro filtro, deverá encaminhá-la à Corte de Cassação ou ao Conselho de Estado, que, em um segundo juízo de admissibilidade, decidirão se cabe reenvio ao Conselho Constitucional para decisão sobre a (in) constitucionalidade da disposição.

Por disposição legislativa se deve entender um texto editado por uma autoridade que detenha poder legislativo. Trata-se, portanto, essencialmente de um texto votado pelo Parlamento (lei, lei orgânica ou medida provisória ratificada pelo Parlamento). Pode ser também uma lei do país da Nova Caledônia. As medidas provisórias não ratificadas, os decretos, os acórdãos ou as decisões individuais não podem, logo, ser objeto de uma questão prioritária de constitucionalidade. Esses são atos administrativos e, como tais, devem ser controlados pelas jurisdições administrativas. ${ }^{15}$

Os direitos e liberdades garantidos pela Constituição de que trata o art. 61-1, por sua vez, são aqueles que figuram:

- na Constituição de 4 de outubro de 1958, com suas alterações;

- nos textos aos quais remete o preâmbulo da Constituição de 4 de outubro de 1958, que formam o que se denomina de bloco de constitucionalidade, a saber: a Declaração de direitos do homem e do cidadão de 1789, o preâmbulo da Constituição de 1946, os princípios fundamentais reconhecidos pelas leis da República (aos quais remete o preâmbulo de 1946, como é o caso da liberdade de associação) e a Carta do Meio Ambiente de $2004^{16}$.

Por sua vez, a lei orgânica regulamentadora a que remete a alínea segunda do artigo 61-1 é a Lei n. 20091523 de 10 de dezembro de 2009. Na decisão n.o 2009-595 DC de 2 de dezembro de 200977, o Conselho Constitucional examinou as disposições dessa lei orgânica, declarando-as constitucionais.

É importante observar que a questão prioritária de constitucionalidade não pode ser a causa ou o objeto principal do julgamento: ela é suscitada como um incidente até que o Conselho Constitucional, sendo o caso, seja provocado a se manifestar. Outra observação relevante é que a QPC não pode ser simplesmente suscitada de ofício pelo juiz. Depende de provocação, conforme já reconhecido pelo Conselho Constitucional ${ }^{18}$.

15 FRANCE. CONSEIL CONSTITUTIONNEL. Découvrir la qpc. Disponível em http://www.conseil-constitutionnel. $\mathrm{fr}$ /conseil-constitutionnel/francais/la-question-prioritaire-de-constitutionnalite/decouvrir-la-qpc/12-questions-pourcommencer.47107.html\#1. Acesso em 8 de setembro de 2016.

16 FRANCE. CONSEIL CONSTITUTIONNEL. Découvrir la qpc. Disponível em http://www.conseil-constitutionnel. $\mathrm{fr} /$ conseil-constitutionnel/francais/la-question-prioritaire-de-constitutionnalite/decouvrir-la-qpc/12-questions-pourcommencer.47107.html\#1. Acesso em 8 de setembro de 2016.

18 FRANCE. CONSEIL CONSTITUTIONNEL. Décision n. 2009-595 DC du 2 décembre 2009 (considérant n. 9). 
Há, pois, um duplo filtro: o primeiro exercido pelo juiz da causa que, sendo ultrapassado, enviará a QPC ao Conselho de Estado ou à Corte de Cassação; o segundo, de competência dessas Cortes Supremas, que só enviarão a QPC ao Conselho Constitucional caso esse segundo juízo de admissibilidade seja positivo.

No próximo item, serão analisados os filtros da QPC em seus detalhes.

\section{Os filtros de acesso ao Conselho Constitucional}

Conforme já mencionado, anteriormente à criação da QPC, o Conselho Constitucional poderia apenas exercitar o controle de constitucionalidade a priori, ou seja, antes que a disposição legislativa entrasse em vigor. Além disso, a iniciativa do controle exercido pelo Conselho Constitucional cabia ao Parlamento ou ao Presidente, mas não ao jurisdicionado.

Com a QPC, foi introduzido no sistema francês o controle de constitucionalidade a posteriori realizado pelo Conselho Constitucional, por iniciativa de uma das partes em um processo tramitando perante a Justiça Comum ou Administrativa.

Caso o juiz do caso admita a QPC, caber-lhe-á remetê-la ao Conselho de Estado ou à Corte de Cassação, conforme o caso, que exercerão um segundo juízo de admissibilidade. Esse duplo juízo de admissibilidade exercido pelos juízes do processo e pelas cortes supremas (Conselho de Estado e Corte de Cassação) tem a evidente intenção de permitir que apenas sejam submetidas ao Conselho Constitucional questões que efetivamente mereçam seu exame.

Depois do capítulo II do título II da medida provisória n. 58-1067 de 7 de novembro de 1958, a a Lei Orgânica do Conselho Constitucional, foi inserido um capítulo II bis tratando da questão prioritária de constitucionalidade ${ }^{19}$. O artigo 23-2 da medida provisória de 7 de novembro de 1958 alterada trata dos critérios que o juiz da causa deve levar em consideração para realizar o primeiro juízo de admissibilidade da QPC. Assim, os critérios que permitem a transmissão da QPC pelo juiz da causa ao Conselho de Estado ou à Corte de Cassação são três e cumulativos e, caso estejam presentes, a QPC será transmitida pelo juiz da causa a uma das cortes supremas em decisão irrecorrível.

O primeiro critério impõe que a disposição seja aplicável ao litígio ou ao procedimento ou constitua o fundamento dos processos.

O segundo critério exige que a disposição ainda não tenha sido declarada conforme à Constituição em seus motivos e dispositivo por uma decisão do Conselho Constitucional, salvo mudança de circunstâncias. O Conselho Constitucional já tem precedente sobre o que significa a mudança de circunstância, como é o caso da decisão n. $2008-573$ DC de 8 de janeiro de $2009^{20}$, em que reconheceu a mudança de circunstâncias em relação à regra que impõe um número de no mínimo dois deputados por departamento. ${ }^{21}$

Além disso, na sua decisão n 2009-595 DC de 3 de dezembro de 2009²2, o Conselho conferiu três características para a ideia de mudança de circunstâncias. Em primeiro lugar, essa mudança pode ser das normas de constitucionalidade aplicáveis, por exemplo, a integração da Carta do Meio Ambiente à Constituição. Em segundo lugar, essa mudança pode ser em relação à mudança das circunstâncias de fato que poderiam afetar o conteúdo da disposição legislativa cuja inconstitucionalidade se suscita. Em terceiro lugar, a contrario sensu e sob pena de esvaziar o conteúdo desse critério, não se deve interpretar a mudança de circunstâncias de fato individuais e próprias do processo.

19 FRANCE. Loi Organique 2009-1523 du 10 décembre 2009. Disponível em http:/ / www.conseil-constitutionnel.fr / conseil-constitutionnel/root/bank_mm/textes/loi_organique_qpc.pdf. Acesso em 22 de de outubro de 2017.

20 FRANCE. Conseil Constitutionnel. Dec. n. ${ }^{\circ}$ 2008-573 DC du 8 janvier 2009.

21 Nesse julgamento, o Conselho Constitucional reconheceu como mudança de circunstâncias uma mudança das circunstâncias de direito (o máximo de 577 deputados fixado pelo Código Eleitoral com fundamento no art. 24 da Constituição) e uma mudança das circunstâncias de fato (o aumento não homogêneo da população no território) para definir o número de deputados por departamento.

22 FRANCE. Conseil Constitutionnel. Décision n. 2009-595 DC du 3 décembre 2009 (considérant 13). 
Ainda em relação a esse segundo critério, na mesma decisão o Conselho Constitucional resolveu que ele não diz respeito à disposição legislativa contestada ${ }^{23}$. Caso assim não se entendesse, toda questão ainda não examinada pelo Conselho seria sempre nova. Esse critério da questão nova deve ser apreciado em relação à disposição constitucional com a qual a disposição legislativa é confrontada. Essa hipótese visa certamente ao caso de uma disposição de estatura constitucional que nunca tenha sido aplicada, especialmente porque ela seria recente, como a Carta do Meio Ambiente.

O terceiro critério é aquele segundo o qual a questão não seja desprovida de caráter sério. A sua finalidade é evitar questões temerárias ou com finalidade protelatória. O caráter sério da questão constitucional suscitada não é definido pela constituição, tampouco pela lei. A tendência é considerar séria uma afronta à Constituição que não seja dilatória ou fantasiosa, absurda, o que também são conceitos assaz abstratos ${ }^{24}$.

Em relação ao segundo juízo de admissibilidade, ou seja, aquele realizado pelas Cortes Supremas (Corte de Cassação ou Conselho de Estado), conforme o art. 23-2, os dois primeiros critérios são idênticos àqueles aplicáveis pelo juiz da causa, ou seja, o primeiro critério impõe que a disposição seja aplicável ao litígio ou ao procedimento ou constitua o fundamento dos pedidos e o segundo exige que a disposição ainda não tenha sido declarada conforme à Constituição em seus motivos e dispositivo por uma decisão do Conselho Constitucional, salvo mudança de circunstâncias.

Em relação ao terceiro critério, o legislador determina que as Cortes Supremas analisem se o QPC apresenta caráter sério ou novo. Em relação à questão da seriedade, é importante registrar que há uma sutil diferença entre a análise desse critério pelo juiz da causa e pelas Cortes Supremas. Enquanto aquele deve analisar se a questão não é desprovida de caráter sério, essa devem verificar se a QPC apresenta caráter sério, redações que de forma muito sutil parecem querer impor um controle mais rígido da questão da seriedade às Cortes Supremas.

Assim, ante as jurisdições de fundo, trata-se somente de se assegurar que a questão não é manifestamente infundada. A condição exigida, por outro lado, das cortes supremas parece mais exigente. Ela é, no entanto, temperada pela condição alternativa concernente à novidade da questão (uma questão nova não é necessariamente séria).

O critério da questão nova alternativa ao caráter sério tem por finalidade evitar que os juízes comuns ou administrativos decidam eles mesmos questões não decididas pelo Conselho Constitucional a pretexto de que a dificuldade não é suficientemente séria, possibilitando, assim, que eles mesmos resolvam descartar a questão. O Conselho Constitucional, assim, tem o seu papel de intérprete da Constituição reforçado. Sua atuação, no quadro do artigo 61-1, não será apenas de censura às disposições legislativas, mas também de assegurar a interpretação uniforme da Constituição, mesmo nos casos em que a disposição legislativa contestada não pareça ser inconstitucional.

Além disso, o Conselho Constitucional entendeu que esse critério da novidade habilitaria o Conselho de Estado e a Corte de Cassação a apreciar, em função desse critério alternativo, a conveniência de acionar o Conselho Constitucional. Poderia, assim, ser qualificada de nova uma disposição legislativa que é objeto de um recurso massivo à QPC e que é oportuno permitir que o Conselho Constitucional a decida definitivamente.

Dessa forma, a referência ao caráter novo da questão como condição alternativa a seu caráter sério evita que os juízes comuns ou administrativos decidam eles mesmos as questões não resolvidas pelo Conselho Constitucional a pretexto de que a dificuldade não é suficientemente séria para que eles mesmo resolvam. Note-se, ainda, que a referência à questão nova na prática parece muito próxima da ideia de mudança das circunstâncias mencionada no critério precedente.

A decisão do Conselho de Estado ou da Corte de Cassacão de não reenvio não admite recurso, mesmo perante o Conselho Constitucional. Há críticas a esse sistema e propostas legislativas para alterá-lo,

23 FRANCE. Conseil Constitutionnel. Décision n. 2009-565 DC du 10 décembre 2009 (considérant 21).

24 STÉFANINI, Marthe Fatin-Rouge. L'appréciation, par les cours suprêmes, du caractère sérieux de la QPC. In: CARTIER, Emmanuel; GAY, Laurence; VIALA, Alexandre (org). La QPC: vers une culture constitutionnelle partagée? Paris: Institut Universitaire Varenne, 2015, p. 29-42. 
o que não ocorreu até o momento. Essas decisões de não reenvio do Conselho de Estado e da Corte de Cassação têm motivações as mais diversas. Umas delas é que o atentado à constituição não é sério. Como nem a Constituição nem a lei estabelece o que quer dizer a seriedade do atentado, é natural que os críticos apontem uma certa dose de o subjetivismo ${ }^{25}$.

Perceba-se que uma das características marcantes do sistema francês é que o Conselho Constitucional é excluído da filtragem das questões prioritárias de constitucionalidade. A escolha de uma filtragem pelo juiz da causa está de acordo com o sistema escolhido, de estautuir a QPC como um controle incidental e como questão prejudicial. A recusa de o juiz da causa remeter a QPC ao Conselho Constitucional ou à Corte de Cassação não pode ser objeto de recurso próprio, mas apenas do recurso da causa. Já da decisão do Conselho de Estado ou da Corte de Cassação de não enviar não cabe qualquer recurso ${ }^{26}$.

A participação do Conselho Constitucional na filtragem nunca foi realmente considerada, em razão de um pretenso risco de estrangulamento do sistema. Alguns juristas franceses acham o argumento fraco, pois o estrangulamento poderia ocorrer nas cortes superiores e o Conselho Constitucional poderia ser dotado de uma câmara exclusivamente para fazer exame de admissibilidade das QPC`s ${ }^{27}$.

Por outro lado, a QPC possibilitou o diálogo entre o Conselho Constitucional e as justiças comum e administrativa, na medida em que o juiz administrativo e o Conselho de Estado ou o juiz comum e a Corte de Cassação analisam a admissibilidade da QPC ${ }^{28}$.

A Corte Europeia de Direitos do Homem (CEDH) validou esse instrumento jurídico pelo qual a Corte de Cassação ou o Conselho de Estado filtram as QPC`s antes de fazer o seu envio ao Conselho Constitucional. Os juízes europeus haviam sido provocados por diversos litigantes franceses em processos fiscais e delitos financeiros. Esses litigantes haviam tentado se insurgir, por meio da QPC, contra a constitucionalidade dos artigos de lei aplicados a seus casos.

Nos casos que foram levados aos juízes europeus, a Corte de Cassação havia negado seguimento às QPC`s sob o argumento de que as questões não eram novas ou não tinham um caráter sério. Esse filtro foi contestado pelos demandantes, sob o argumento de que a negativa de prosseguimento da parte da Corte de Cassação atentava contra o seu direito de acesso à justiça. A Corte Europeia não acolheu seus pleitos em uma decisão definitiva, forte no entendimento de que os juízos de admissibilidade exercidos pela Corte de Cassação e pelo Conselho de Estado não vão de encontro com a Convenção Europeia de Direitos do Homem ${ }^{29}$.

\section{Os primeiros anos de aplicação da QPC}

Em relação à aplicação dos filtros de acesso da QPC ao Conselho Constitucional, há atores processuais, notadamente advogados, que temiam uma utilização muito rigorosa dos filtros processuais ${ }^{30}$. No entanto, após alguns anos de aplicação, parece que há um certo consenso de que a aplicação dos filtros pelos juízes de fundo e cortes supremas tem sido em uma medida mais ou menos justa.

25 PERRIER, Jean-Baptiste. Le non-renvoi des questions prioritaires de constitutionnalité par la Cour de Cassation. Revue Française de Droit Administratif, Paris, n. 4, pp. 711-722, Juillet-Aôut 2011.

26 VIDAL-NAQUEL, Ariane. Le rôle du Conseil Constitutionnel Français. Annuaire International de Justice Constitutionnelle, Presses Universitaires, Aix-en-Provence, XXVII, p. 41-53, 2011.

27 VIDAL-NAQUEL, Ariane. Le rôle du Conseil Constitutionnel Français. Annuaire International de Justice Constitutionnelle, Presses Universitaires, Aix-en-Provence, XXVII, p. 41-53, 2011.

28 LESSI, J; DUTHEILLET DE LAMOTHE. Cinq ans de QPC devant lu juge administratif: retour d'experience. AJDA, Paris, p. 755-771, 2015.

29 LE PARISIEN. Disponível em http:/ / www.leparisien.fr / strasbourg-67000/la-cedh-valide-le-mecanisme-de-filtredes-qpc-17-09-2015-5101069.php. Acesso em 20/10/2016.

30 GROS, Manuel. Une rédefinition dynamique des rapports entre les acteurs du procès. In: CARTIER, Emmanuel (coord.). La QPC, le procès et ses juges. L'impact sur le procès et l'architecture jurisdictionnelle. Paris: Dalloz, 2013. 
Enquanto a Corte de Cassação parece permitir a remessa ao Conselho Constitucional de uma quantidade maior de matérias, o Conselho de Estado retém uma quantidade maior de matérias. Isso tem levado os críticos a dizer que o Conselho de Estado está se tornando, de certa forma, um Tribunal Constitucional por vias transversas ${ }^{31}$.

A crítica não é desprovido de sentido. A filtragem da QPC pelas duas cortes supremas lhes permite interpretar a lei em um sentido que seja conforme à constituição e assim julgar a QPC não séria. A interpretação conforme é um instrumento muito eficaz, aplicável quando não existir flagrante contradição entre os termos da disposição legislativa e aqueles da Constituição.

Utilizando esta técnica, o Conselho de Estado e a Corte de Cassação se transmutam em juízes constitucionais, de certa forma: podem interpretar a disposição legislativa contestada em um sentido que estimem conforme à constituição para julgar, ao mesmo tempo, que a questão de constitucionalidade não é séria e que não há lugar para reenvio ao Conselho Constitucional. Para fazê-lo, elas podem se inspirar na jurisprudência constitucional e propor interpretações neutralizantes, construtivas, até mesmo corretivas, da lei à imagem daquelas formuladas pelo Conselho Constitucional.

De qualquer forma, apesar das críticas, o sistema parece estar funcionando de maneira mais ou menos adequada. Conforme registrado perante a Comissão o Sr. Jean-Marc Sauvé, Vice-Presidente do Conselho de Estado, a taxa de reenvio ao Conselho Constitucional das QPC`s que foram transmitidas ao Conselho de Estado ou apresentadas perante ele diretamente se manteve notavelmente estável: foi de $26 \% \mathrm{em}$ 2010, 25\% em 2011 e 21\% em 2012, ou seja, 24,3\% na média do período, sendo 84,9\% denegados por ausência de seriedade ou de novidade da questão ${ }^{32}$.

Em relação à Corte de Cassação, entre 1.ํ de março de 2010 e 31 de outubro de 2012, 18,9 \% das questões submetidas tiveram juízo de admissibilidade positivo (1217 questões foram apresentadas no total). A falta de seriedade da questão foi responsável por 78,5\% dos casos de negativa de admissibilidade ${ }^{33}$.

É fato que a QPC ampliou a jurisprudência do Conselho Constitucional e sua visibilidade. Desde a sua adoção, as decisões do Conselho sobre QPC`s superaram numericamente suas decisões a priori por praticamente três para uma. E o Conselho está progressivamente intervindo em fases mais iniciais dos procedimentos. Ao mesmo tempo em que se tem verificado essa expansão, o Conselho tem tomado cuidado em ser explicitamente deferente ao Parlamento - insistindo que o Poder Legislativo também tem um papel na interpretação da Constituição.

Essa preocupação (dificuldade contramajoritária) pode estar subjacente à cuidadosa abordagem do Conselho Constitucional em relação ao recente estado de emergência decretado na França após os atentados terroristas de novembro de 2016. O Conselho declinou de censurar a legislação de emergência que permite inúmeras restrições à liberdade de ir e vir dos indivíduos, inclusive toques de recolher, revistas policiais várias vezes por dia ou prisão temporária.

Agindo dessa forma, o Conselho Constitucional explicitamente citou o papel do Parlamento em implementar a Constituição e em determinar o escopo de direitos e liberdades na França, decidindo que uma QPC não era o instrumento adequado para contestar a compreensão do parlamento sobre o seu papel constitucional - uma questão que presumivelmente vai além de direitos subjetivos e, por essa razão, apenas poderia ser suscitada em sede do controle a priori ${ }^{34}$.

31 ROBLOT-TROIZIER, Agnès. Le non-renvoi des Questions Prioritaires de Constitutionnalité par le Conseil d'État. Vers la mutation du Conseil d'État en Juge Constitutionnel de la Loi. Revue Française de Droit Administratif. Paris, n. 4, p. 691-697, Juillet-Aôut 2011.

32 FRANCE. ASSEMBLE NATIONALE. Rapport sur la question prioritaire de constitutionnalité. Disponível em http:/ / www.assemblee-nationale.fr/14/rap-info/i0842.asp. Acesso em 03 de março de 2017.

33 FRANCE. ASSEMBLE NATIONALE. Rapport sur la question prioritaire de constitutionnalité. Disponível em http:/ / www.assemblee-nationale.fr/14/rap-info/i0842.asp. Acesso em 03 de março de 2017..

34 KING, Alyssa S. As Jean-Louis Debré's Term as President Comes to a Close-Whither the French Constitutional Council? Int'l J. Const. L. Blog. Disponível em http://www.iconnectblog.com/2016/01/as-jean-louis-debres-term-aspresident-comes-to-a-close-whither-the-french-constitutional-council. Acesso em 15/8/2017. 


\section{Conclusão}

Conforme já explicitado, este artigo tem por fim inaugurar uma série de trabalhos analisando as Cortes, Tribunais e Conselhos Constitucionais de democracias contemporâneas, bem como as formas como o jurisdicionado pode acessar a jurisdição desses órgãos constitucionais para a obtenção de um pronunciamento sobre a constitucionalidade/inconstitucionalidade de um ato normativo.

A intenção da série de estudos inaugurada pelo presente trabalho é permitir aos interessados no assunto a compreensão das especificidades dos sistemas a serem analisados, tanto como seus órgãos constitucionais são estruturados, quanto como se pode acessar as sua jurisdições, em tempos em que o controle judicial de constitucionalidade é uma tônica nas principais democracias contemporâneas.

Dessa forma, este artigo, que inaugura a série a partir da análise do controle de constitucionalidade pelo Conselho Constitucional da França, começou por explorar a forma como o controle de constitucionalidade foi exercido naquele país na fase pós-revolucionária, até culminar na reforma constitucional de 2008, que introduziu naquele sistema o instrumento que veio a ser denominado pela legislação infraconstitucional de questão prioritária de constitucionalidade, ou, simplesmente, de QPC.

A QPC mudou radicalmente a tradição do controle de constitucionalidade exercido pelo Conselho Constitucional no sistema francês em relação a diversos aspectos, cabendo destacar nesta conclusão duas dessas mudanças: (i) a possibilidade de controle a posteriori de uma disposição legislativa, ou seja, a partir do momento em ela já está em vigor, o que não era permitido antes da reforma; (ii) a possibilidade de um jurisdicionado em um processo tramitando perante a justiça comum ou a justiça administrativa suscitar a QPC.

Essas alterações fundamentais reconfiguraram radicalmente o controle de constitucionalidade na França em ordem a torná-lo mais democrático, mais efetivo e aproximá-lo de diversos outros sistemas na Europa.

Em relação ao juízo de admissibilidade ou filtros de acesso para que uma QPC suscitada por um jurisdicionado seja efetivamente analisade pelo Conselho Constitucional, eles atuam em dois momentos: o primeiro é um juízo de admissibilidade realizado pelo juiz da causa e apenas em caso de ser positivo é que a QPC será reenviada ao Conselho de Estado ou à Corte de Cassação, a depender de a causa estar em tramitação perante a justiça administrativa ou a justiça comum, respectivamente. Em um segundo momento, essas cortes supremas realizarão um segundo juízo de admissibilidade, sendo apenas em caso afirmativo remetida a QPC à efetiva análise do Conselho Constitucional.

Apesar de muito se ter controvertido acerca desses filtros, sempre sob o temor de que dificultassem desmesuradamente o acesso à jurisdição do Conselho, após alguns anos de aplicação, parece que há um certo consenso de que a aplicação dos filtros pelos juízes de fundo e cortes supremas tem sido mais ou menos em uma medida justa.

Dessa forma, pretende-se haver iniciado uma contribuição sobre algumas cortes constitucionais e, especificamente, os filtros postos pelos ordenamentos respectivos para acessá-las, como uma forma de compreender o nosso próprio sistema de acesso ao Supremo Tribunal Federal, objetivo que se pretenderá lograr atingir de forma mais completa ao fim da série de artigos ora inaugurada.

\section{Referências}

ALMEIDA, Domingos Augusto Paiva de. O controle de constitucionalidade na França. Revista de Informação Legislativa, Brasília, n. 144, ano 36, p. 197-210, out-dez/1999.

CONSTANTINESCO, Vlad; PIERRÉ-CAPS, Stéphane. Droit Constitutionnel Français. Paris: Licence Puf, 2010. 
FRANCE. ASSEMBLE NATIONALE. Rapport sur la question prioritaire de constitutionnalité. Disponível em http://www.assemblee-nationale.fr/14/rap-info/i0842.asp. Acesso em 03 de março de 2017.

FRANCE. Conseil Constitutionnel. Dec. n. ${ }^{2} 2008-573$ DC du 8 janvier 2009.

FRANCE. Conseil Constitutionnel. Décision n. 2009-595 DC du 3 décembre 2009 (considérant 13).

FRANCE. Loi Organique 2009-1523 du 10 décembre 2009. Disponível em http://www.conseilconstitutionnel.fr/conseil-constitutionnel/root/bank_mm/textes/loi_organique_qpc.pdf. Acesso em 22 de de outubro de 2017.

FRANCE. CONSEIL CONSTITUTIONNEL. Découvrir la qpc. Disponível em http://www.conseilconstitutionnel.fr/conseil-constitutionnel/francais/la-question-prioritaire-de-constitutionnalite/ decouvrir-la-qpc/12-questions-pour-commencer.47107.html\#1. Acesso em 8 de setembro de 2016.

FRANCE. CONSEIL CONSTITUTIONNEL. Décision n. 2009-595 DC du 2 décembre 2009.

GROS, Manuel. Une rédefinition dynamique des rapports entre les acteurs du procès. In: CARTIER, Emmanuel (coord.). La QPC, le procès et ses juges. L’impact sur le procès et l'architecture jurisdictionnelle. Paris: Dalloz, 2013.

GUILLAUME, Marc. La Question Prioritaire de Constitutionnalité. Disponível em http://www.conseilconstitutionnel.fr/conseil-constitutionnel/francais/la-question-prioritaire-de-constitutionnalite/ decouvrir-la-qpc/la-question-prioritaire-de-constitutionnalite-par-marc-guillaume.138360.html. Acesso em $09 / 09 / 2016$.

KING, Alyssa S. As Jean-Louis Debré's Term as President Comes to a Close-Whither the French Constitutional Council? Int'l J. Const. L. Blog. Disponível em http://www.iconnectblog.com/2016/01/ as-jean-louis-debres-term-as-president-comes-to-a-close-whither-the-french-constitutional-council. Acesso em 15/8/2017.

LESSI, J; DUTHEILLET DE LAMOTHE. Cinq ans de QPC devant lu juge administratif: retour d'experience. AJDA, Paris, p. 755-771, 2015.

LE PARISIEN. Disponível em http://www.leparisien.fr/strasbourg-67000/la-cedh-valide-lemecanisme-de-filtre-des-qpc-17-09-2015-5101069.php. Acesso em 20/10/2016.

PACTET, Pierre. Que sais-je? Les institutions françaises. Presses Universitaires de France. 1983, 3. ${ }^{\underline{a}}$ edição, Paris, Presses Universitaires de France

PERRIER, Jean-Baptiste. Le non-renvoi des questions prioritaires de constitutionnalité par la Cour de Cassation. Revue Française de Droit Administratif, Paris, n. 4, pp. 711-722, Juillet-Aôut 2011.

ROBLOT-TROIZIER, Agnès. Le non-renvoi des Questions Prioritaires de Constitutionnalité par le Conseil d'État. Vers la mutation du Conseil d'État en Juge Constitutionnel de la Loi. Revue Française de Droit Administratif. Paris, n. 4, p. 691-697, Juillet-Aôut 2011.

ROUSSEAU, Dominique. Droit du contentiux constitutionnel. Paris: Editions Montchrestien. 9eme edition. 2010.

STÉFANINI, Marthe Fatin-Rouge. L'appréciation, par les cours suprêmes, du caractère sérieux de la QPC. In: CARTIER, Emmanuel; GAY, Laurence; VIALA, Alexandre (org). La QPC: vers une culture constitutionnelle partagée? Paris: Institut Universitaire Varenne, 2015, p. 29-42.

VIDAL-NAQUEL, Ariane. Le rôle du Conseil Constitutionnel Français. Annuaire International de Justice Constitutionnelle, Presses Universitaires, Aix-en-Provence, XXVII, p. 41-53, 2011. 